\title{
A EDUCAÇÃO FÍSICA NO CONTEXTO DA LDB 9394/96
}

\author{
PHYSICAL EDUCATION IN THE CONTEXT OF LDB 9394/96
}

\section{Rui Anderson Costa Monteiro}

Universidade Nove de Julho - Uninove/SP E-mail: profruianderson@gmail.com

\section{RESUMO}

Segundo a LDB 9.394/96 a Educação Física é componente curricular obrigatório, apresentando algumas possibilidades que permitem ao aluno não participar das aulas. Essa norma também deixa obscuro quanto ao perfil profissional responsável por tal disciplina. Apresentamos como questão norteadora o entendimento da Educação Física no contexto da Lei de Diretrizes e Bases da Educação Nacional. O objetivo deste trabalho consistiu em analisar a facultatividade da Educação Física prevista nesta lei e discutir sobre o professor legalmente constituído para lecioná-la. Tratou-se de uma revisão documental, de caráter exploratório e, analisada qualitativamente. Consideramos que a Educação Física no documento ora pesquisado ainda é marcada fortemente pelas concepções médicas utilitaristas e sem definição clara sobre o perfil profissional responsável pelo seu conteúdo.

Palavras-chave: Lei de Diretrizes e Bases; Educação Básica; Educação Física Escolar.

\section{ABSTRACT}

According to LDB 9.394/96, Physical Education is a compulsory curricular component, presenting some possibilities that allow the student not to participate in classes. This norm also leaves it unclear as to the professional profile responsible for such discipline. We present as a guiding question the understanding of Physical Education in the context of the Law of Guidelines and Bases of National Education. The objective of this work was to analyze the option of Physical Education foreseen in this law and to discuss about the legally constituted teacher to teach it. It was a documentary review, of an exploratory nature and analyzed qualitatively. We believe that Physical Education in the document now researched is still strongly marked by utilitarian medical conceptions and without a clear definition of the professional profile responsible for its content.

Keyword: Law of Guidelines and Bases; Basic education; School Physical Education. 


\section{INTRODUÇÃO}

A Educação Física (EF) no Brasil apresenta uma história rica em debates na busca pela legalização e sua respectiva legitimação na sociedade. $\mathrm{O}$ resultado deste processo é sua regulação em Bacharelado e Licenciatura, essa última pautada na Lei de Diretrizes e Bases da Educação Nacional 9.394/1996 (LDBEN) em que, no parágrafo $3^{\circ}$ do artigo 26 , é colocada como componente curricular obrigatório (BRASIL, 1996).

A LDBEN passou por inúmeras alterações, incluindo a própria Educação Física em 2003. Essa mudança trouxe condições para a EF não ser realizada pelo aluno, sem deixar explícitas as justificativas para tal, isso resultou em regras amplas e de difícil entendimento, somando-se à falta de clareza sobre a formação exigida do profissional responsável pela disciplina dentro da escola. Dessa forma, apresentamos como problema de pesquisa o seguinte questionamento: Qual a interpretação sobre a Educação Física na LDBEN 9.394/96 envolvendo a facultatividade na participação do aluno e a formação exigida ao professor? Por meio da análise qualitativa realizada na revisão documental de caráter exploratória, entrecruzamos a LDBEN (BRASIL, 1996) que regula a disciplina e os principais documentos curriculares: Parâmetros Curriculares Nacionais - PCNs (BRASIL, 1997) e Base Nacional Comum Curricular - BNCC (BRASIL, 2017) em busca da interpretação e compreensão sobre a fundamentação da Educação Física no contexto escolar. O trabalho se justificou pelo fato deste conhecimento ser relevante no processo de ensino e aprendizagem dentro do ambiente escolar e ainda possuir imprecisões em relação à sua normatização educacional.

\section{O contexto da Educação Física na Lei}

Segundo a LDBEN 9.394/96, em seu artigo 26, os currículos de toda Educação Básica precisam estar alinhados a uma base nacional comum e registra a Educação Física como componente obrigatório de maneira integrada à proposta pedagógica do estabelecimento de ensino. Porém, mesmo que compulsória, a lei coloca como prática facultativa aos seguintes alunos:

I - que cumpra jornada de trabalho igual ou superior a seis horas; II - maior de trinta anos de idade; III - que estiver prestando serviço militar inicial ou que, em situação similar, estiver obrigado à prática da educação física; IV amparado pelo Decreto-Lei no 1.044, de 21 de outubro de 1969; V - (VETADO) e VI - que tenha prole (BRASIL, 1996, Art. 26, § $3^{\circ}$ ).

Quando da aprovação da LDBEN em 1996, a lei não trazia o termo obrigatório e era opcional somente para quem estudasse no período noturno. Em 1999, pouco tempo depois de sua aprovação, tramitou no Congresso Nacional o Projeto de Lei 1.467B/1999 de autoria do então Deputado Federal Florisvaldo Fier, conhecido como Dr. Rosinha (Médico no Estado do Paraná), e o resultado foi a aprovação da Lei 10.793/2003 dando nova redação ao dispositivo conforme descrito acima.

De acordo com a justificação na tramitação do referido Projeto de Lei (BRASIL, 2000) a Educação Física facultativa aos cursos noturnos ocasionaria discriminação do aluno trabalhador, pois ao ser obrigado estudar à noite, não teria direito de acessar a disciplina, permitindo ainda duplo sentido sobre ser ou não opcional à escola ofertar tal conteúdo. $\mathrm{O}$ novo texto se fundamentou na isonomia de direito à Educação Física entre os períodos de estudo e observou que o ajuste às faixas etárias e às condições da população escolar aproximava-se ao perfil do estudante pertencente ao mercado de trabalho e, por isso, apesar de oferta obrigatória, a participação era opcional aos alunos atuantes na economia. Para tentar dar mais especificidade, foram apresentadas as condições já mencionadas.

Ao observarmos este cenário, indagamos o seguinte: será que o aluno com jornada igual ou superior a seis horas diárias estará tão cansado ao ponto de não poder discutir sobre a importância da atividade física para a saúde? Alguém maior de trinta anos de idade não poderia trocar experiências sobre os jogos e as brincadeiras de seu tempo de infância, ou mesmo participar de vivências práticas durante a aula? Aquele prestando serviço militar inicial não pode refletir sobre os esportes e a origem da própria Educação Física? O aluno impossibilitado de realizar movimentos corporais por atestado médico, mas presente na aula, não poderia estudar assuntos do corpo humano ou participar de outras modalidades (jogos de tabuleiro, por exemplo)? E o que dizer sobre alunos que têm filhos? Nenhum destes argumentos parecem se justificar para tornar a participação facultativa, em meio à obrigatoriedade das outras disciplinas.

Destacamos que a Educação Física vivenciou longa crise de identidade a partir dos anos 80/90 fazendo emergir a concepção de cultura (BETTI, 2007), isso por conta do crescimento dos estudos para entender as mudanças e as possibilidades de análise em torno do seu referido objeto de estudo. Durante a década de 1990 o Ministério da Educação aprovou os Parâmetros Curriculares Nacionais (BRASIL, 1997) apoiando-se numa proposta democratizante a este componente, com foco na humanização do aluno, por meio da diversificação das práticas pedagógicas. Tão logo, buscava-se transcender a perspectiva técnico-biológica em função das dimensões socioculturais, afetivas e cognitivas 
V.10 N.1 (2022) ISSN: 2317-434X

condizentes ao movimento humano.

A Educação Física recebeu grande contribuição de teorias críticas propondo a cultura corporal de movimento como objeto de estudo (BETTI, 2007), colaborando para inserir e enriquecer discussões políticas, sociais e históricas das práticas corporais, já que se tratava de um fenômeno não reduzido aos aspectos morfofuncionais. Nos PCNs (BRASIL, 1997) somado à formação do físico, essa disciplina apresenta objetivos educacionais intelectuais e conteúdos pedagógicos mais humanísticos.

Observamos falta de coerência na questão deste componente curricular quando se resume em atividades a promover desenvolvimento da aptidão física, pois é preciso ir além do "fazer atividades", considerando o fato da Educação Física ser composta por elementos e temáticas diversificadas da cultura corporal, a fim de superar o caráter esportivista e procedimental (BOSCATTO; DARIDO, 2018).

A Base Nacional Comum Curricular - BNCC trouxe como mudança a inclusão da Educação Física na área de Linguagem e esta recebeu tratamento no âmbito da cultura. Isso definiu abordagens de estudo para além do saber fazer (movimento), voltadas às expressões culturais e pensadas teoricamente. A Educação Física é colocada como responsável por tematizar lutas, danças, jogos e brincadeiras, práticas corporais de aventura, ginásticas e esportes, favorecendo o experimentar, a fruição, reflexão da ação, construção e compreensão de valores, no sentido da formação para o protagonismo do aluno (BRASIL, 2017). Portanto, este componente curricular tem se estabelecido no ambiente escolar na perspectiva culturalista a fim de conduzir os alunos à compreensão da multiplicidade de conteúdos e possibilidades de entendimento da cultura corporal de movimento.

A BNCC reforça este entendimento, trata-se da mais recente política pública na área da educação apoiada na LDB e traz em seu conjunto os direitos e objetivos de aprendizagem em cada etapa da Educação Básica, sendo a Educação Física componente de relevância social, inserida na área de Linguagens para contribuir nos estudos das complexas relações pessoais e institucionais, buscando a preservação e reconstrução crítica da herança históricosocial da humanidade vinculada à perspectiva sociocultural por meio das práticas corporais (RUFINO; BENITES; NETO, 2020).

\section{Quem pode ministrar a aula?}

Sobre o professor responsável pela Educação Física, a LDBEN flexibiliza a formação no sentido de permitir ao pedagogo e ao técnico em magistério conduzir tal aula. A figura do especialista em Educação Física na Educação Básica é exigida a partir do Ensino Fundamental II (anos finais) e Ensino Médio. O problema mora na condição que se dá à formação inicial destes profissionais da Educação Infantil e do Ensino Fundamental (anos iniciais), pois, provavelmente, o conhecimento sobre as manifestações corporais seja abordado de maneira superficial. Estamos falando de um curso (Magistério) em extinção e os atuais cursos de Pedagogia aligeirados, com foco na alfabetização, em que o movimento corporal se resume muitas vezes ao jogar e brincar de forma livre e quem sabe, até sem planejamento pedagógico.

Atualmente, tramita pelo Congresso Nacional o Projeto de Lei 488/2015 (BRASIL, 2015) visando dar nova redação ao parágrafo $3^{\circ}$ do artigo 26 da LDBEN, o que colaborará para um novo status da Educação Física no exercício do magistério, porquanto somente licenciados na área atuará com essa disciplina.

\section{$\S 3^{\circ}$ A educação física, integrada à proposta pedagógica da escola e aos programas e projetos educacionais dos sistemas de ensino, é componente curricular obrigatório da educação básica, a ser ministrado por profissional devidamente habilitado na área, sendo sua prática facultativa ao aluno: [...] (BRASIL, 2015, s/p)}

Essa proposta, se aprovada, irá gerar reserva de mercado aos professores licenciados em Educação Física sob o argumento da melhor formação à prática docente $\mathrm{e}$ provavelmente colocará um ponto final aos conflitos em torno deste assunto, não permitindo mais ao profissional generalista (pedagogos e os técnico de nível médio magistério) a condução deste componente curricular.

A formação inicial em Educação Física (Licenciatura) apresenta características próprias e se faz necessário ter clareza dessas particularidades a fim de não ocorrer em práticas pedagógicas afastadas de base teóricoprática consistente e atuação profissional superficial (METZER; DRIGO, 2020), resultando em aulas que não desenvolvam as unidades temáticas previstas na $\mathrm{BNCC} \mathrm{e}$ esteja desalinhada à perspectiva da cultura corporal de movimento. 


\section{V.10 N.1 (2022) ISSN: 2317-434X}

\section{Considerações finais}

A legislação apresenta um viés biológico e utilitarista sobre a Educação Física. Essa situação provavelmente ocorreu pelo perfil do autor do projeto inicial (médico e político), somado ao período histórico da tramitação. Por sua vez, os documentos curriculares a colocam numa dimensão teórico-prática multidimensional (biológico, psicológico, cultural, social, político, econômico, etc.) na perspectiva da cultura corporal de movimento. A prática facultativa parece-nos incoerente na atualidade, as questões ora apresentadas não se justificam no contexto do ensino regular, pois a Educação Básica está fundada na difusão multicultural. Somado a isso, temos a imprecisão teórica sobre o profissional responsável, talvez pela falta de professores que um dia foi flagrante na educação brasileira, todavia, também não se justifica mais, principalmente pelas especificidades dos conhecimentos a serem estudados.

Acreditamos serem urgentes mudanças na respectiva Lei, de forma a dar mais clareza ao objeto discutido neste trabalho e não aumentar o tratamento secundarizado deste componente curricular no processo educacional, fazendo a legislação acompanhar todo conhecimento científico produzido em torno da Educação Física.

\section{REFERÊNCIAS}

BETTI, Mauro. BETTI, Mauro. Educação física e cultura corporal de movimento: uma perspectiva fenomenológica e semiótica. Journal of Physical Education, v. 18, n. 2, p. 207-217. Maringá-PR, 2007.

BOSCATTO, Juliano Daniel; DARIDO, Suraya Cristina. Currículo e educação física escolar: análise do estado da arte em periódicos nacionais. Journal of Physical Education, v. 28. Maringá-PR, 2018.

BRASIL. Lei no 9.394, de 20 de dezembro de 1996. Estabelece as Diretrizes e Bases da Educação Nacional. Congresso Nacional. DF: Brasília, 1996.

BRASIL. Secretaria de Educação Fundamental. Parâmetros Curriculares Nacionais: Educação Física/Secretaria de Educação Fundamental. MEC/SEF. DF: Brasília, 1997. 96p.

BRASIL. Projeto de Lei $n^{0}$ 1.467-B/1999. Diário da Câmara dos Deputados n ${ }^{\circ}$ 208, de 8 de dezembro de 2000 - Câmara dos Deputados. DF: Brasília, 2000.
BRASIL. Projeto de Lei do Senado $\mathrm{n}^{\circ}$ 488, de 16 de julho de 2015. Altera a Lei $\mathrm{n}^{\circ} 9.394$, de 20 de dezembro de 1996, que estabelece as diretrizes e bases da educação nacional - LDB, para valorizar e incentivar o desporto escolar. Congresso Nacional. DF: Brasília, 2015.

BRASIL. Secretaria de Educação Básica. Base Nacional Comum Curricular: BNCC. MEC/CNE. DF: Brasília, 2017.

METZNER, Andreia Cristina; DRIGO, Alexandre Janotta. Os elementos que marcam as especificidades na formação de professores de Educação Física. Revista Motrivivência, v. 32, n. 63, p. 1-19. Florianópolis, 2020.

RUFINO, Luiz Gustavo Bonatto; BENITES, Larissa Cerignoni; DE SOUZA NETO, Samuel. Formação de professores de Educação Física no Brasil: análise das políticas públicas e implicações para o desenvolvimento da prática profissional. Revista Corpoconsciência, p. 226-240. Cuiabá, 2020. 